\title{
Iron ore filtration process improvement through pH modification
}

\author{
Alexandre Gonçalves Andrade ${ }^{1}$ (1) $\cdot$ Maycon Athayde ${ }^{2}$
}

Received: 4 May 2020 / Accepted: 25 February 2021 / Published online: 6 March 2021

(C) The Author(s) $2021 \quad$ OPEN

\begin{abstract}
The present study presents the effect of $\mathrm{pH}$ reduction in iron ore slurry for an iron ore filtration process. A reduction on moisture content and increase on filters throughput was proposed by the $\mathrm{pH}$ modification. The experimental procedure included bench scale tests and industrial scale up of the observed results. Additionally, Langelier's saturation index was applied to determine the optimum $\mathrm{pH}$ range for the filtration operation. The calcium carbonate deposition test was developed and evaluated in the present study. A comprehensive evaluation at different $\mathrm{pH}$ ranges was performed leading to identify the calcium carbonate deposition critical point.
\end{abstract}

Keywords Filtration process · Iron Ore $\cdot$ Moisture $\cdot$ Langelier saturation index

\section{Introduction}

The water quality is a key parameter for liquid-solid separation processes, nonetheless in industrial iron ore operation this variable is sometimes neglected due to upstream constraints, such as water availability, treatment or even contribution of an upstream operational unit. The last one, for instance, it is the burnt lime is typically added to the slurry to mitigate settlement risk during eventual pipeline shutdown, in most operations. The dynamic viscosity increases [1] and higher particle suspension stability avoids plugs in pipeline, consequently improving operational reliability [2]. Historically, optimum slurry $\mathrm{pH}$ was identified and set as 11.5, which is considerably higher than the optimum for dewatering operation, impacting downstream processes. The vacuum filtration process is strongly sensitive to the slurry electrostatic conditions, mainly due to the particle dispersion and aggregation state of particles in suspension. In bench scale leaf test filtration [3] studies, it has been observed a maximum throughput and a minimum filter cake moisture content at $\mathrm{pH}$ level of 6.8. On the other hand, [3] studies evaluating iron ore quality shows an optimum $\mathrm{pH}$ higher than 10.4, however assuming the need to increase lime addition at the pipeline (where minimum $\mathrm{pH}$ of 10.0 is required for the safe issues).

The water chemistry plays an important role, the impact of lime, or $\mathrm{pH}$ increase, lead to the precipitation of insoluble calcium hydroxide and allow the conversion of soluble calcium hydroxide-complex which dissociates into ions $\mathrm{Ca}^{++}, \mathrm{OH}^{-}$and $\mathrm{CaOH}^{+}$[3]. Additionally, the carbonic acid, carbonate and bicarbonate concentration in solution are strongly linked to $\mathrm{pH}$ and carbon dioxide concentration. At pH level lower than 4.0 the carbon dioxide is unstable in solution and easily released back to the atmosphere. In the $\mathrm{pH}$ ranging from 4.4 to 8.4 , there are presence of bicarbonates soluble ions, and by contrast insoluble carbonates ions are likely to occur in the $\mathrm{pH}$ level between 8.4 and 9.6. In more alkaline environment, carbon dioxide is converted into insoluble carbonate [4]. In meanwhile, there are a range between the neutral and more alkaline slurry which can optimize the pellet feed production, however it can bring scale formation risk to occur in the ducts and pumps due the carbonate precipitation.

From the filtration perspective, the mineral particles coagulation is strongly influenced by the adsorption of

Alexandre Gonçalves Andrade, xandyandrade@gmail.com | ${ }^{1}$ Sept-îles, Québec, Canada. ${ }^{2}$ Vale SA, Av. Dante Micheline, 5500-Ponta de Tubarão, Vitoria-ES, Espírito Santo 29090-900, Brasil. 


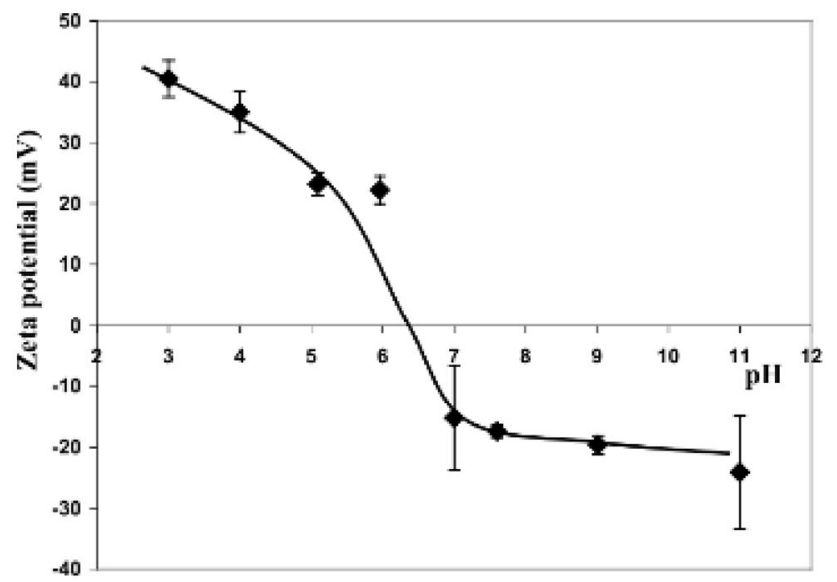

Fig. 1 Hematite zeta potential as a function of $\mathrm{pH}[9]$

positive and negatives electrical charged species onto the particles, modifying the filtration behaviour. The slurry stability has been demonstrated by Turrer et al. [3] as an important variable of the filtration process. The stability of the suspension is observed by the neutrality of charges over the hematite particle (zeta potential). The pellet feed fraction should have a proper flocculation of the finer fraction [1]. Solution electrostatic parameter is also dependent on slurry $\mathrm{pH}$ ranges [5]. Eisele et al. [6] observed that $\mathrm{Ca}++$ strongly adsorb onto the particles surfaces when the slurry $\mathrm{pH}$ is superior to point of zero charge (PZC) at the zeta potential tests. Carlson and Kawatra [7] reviewed several studies showing PZC around pH 6.0 to 8.0 for hematite. For the Alegria's iron ore, Lopes et al. [8] found the optimum $\mathrm{pH}$ value of 7.0 for hematite ore flotation process (Fig. 1).

Pan [9] and Quast [10] have studied point of zero charge (PZC) as a function of $\mathrm{pH}$ for hematite particles. The point of zero charge for hematite was achieved at $\mathrm{pH} 6.5$ using cationic dendrimer and Zeta-meter 3.0 and Zeta Potential Analyzer Version 2.18 (Brookhaven Instruments Corp.).
The present study evaluates the iron ore slurry transferred from a beneficiation plant to the filtration unit in a long range pipeline. Iron ore slurry is received in buffer tanks and distributed to vacuum filter discs. Vacuum disk filters remove water from slurry to produce a filter cake with outcome moisture content ranging $10 \%$ to $11 \%$. A complex arrangement of physical-chemical parameters strongly impact the solid-liquid process efficiency among them: particle size, morphology, filter cloth and water quality [3].

As in typical in pipeline operations, burnt lime is used to avoid plugs and incidents. Although, according to the run of mine (ROM) quality decrease, grinding energy in the beneficiation process has increased, then resulting in changes in slurry viscosity. Indeed, burnt lime dosage could be increased as a countermeasure to the changes in mine lithology and the $\mathrm{CO}_{2}$ injection to control the $\mathrm{pH}$ at the filtration process is possible practice. The impact of the insoluble calcium carbonate is drastic for the filtration process, reducing fabric cloths lifetime from 800 to $250 \mathrm{~h} /$ month. In a study from Silva et al. [5] was observed calcium carbonate and iron oxide deposition in vacuum pumps, ducts and filtration sectors. Figure 2 shows some examples of calcium carbonate and iron hydroxides deposition. Calcium carbonate and iron hydroxide formation strongly influences the filtration process, since fabric clothes loses permeability and lifetime. Iron hydroxide is represented by the red portion deposited in the pumps at Fig. 2a. Calcium carbonate is represented by the white build-up formation represented in the Fig. $2 \mathrm{~b}$. The mixture of calcium carbonate and iron hydroxide is represented in the Fig. 2c. Scale built up in pipes and pumps have reduced the total amount of slurry for the filters and pumps capacity. Sectors were affected by the permeability reduction caused by this deposition.

Despite of that, the current slurry $\mathrm{pH}$ level used at the filtration plant is in the range of 11.0-11.5, to allow proper filtration performance and prevent scale formation.

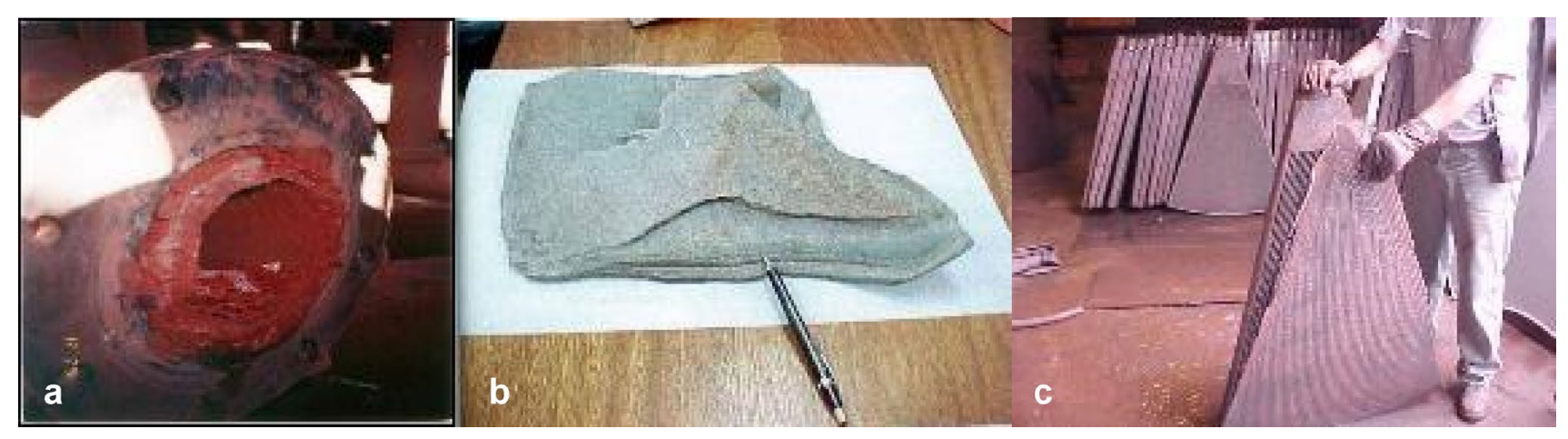

Fig. 2 Calcium carbonate and iron hydroxide deposition typical in the filtration plant. a Calcium carbonate and iron hydroxide deposited pipes, $\mathbf{b}$ filter cloth fragilized by calcium carbonates and iron hydroxide, $\mathbf{c}$ Layer of calcium carbonates and iron hydroxide 
Additionally, in the past, the plant has experienced a large scale formation associated with the strong use of lime in pipeline. According to Langelier [4], the easier way to reduce the $\mathrm{pH}$ is recarbonating the solution by the insertion of $\mathrm{CO}_{2}$ gas, this is a chemical procedure to transform carbonates into soluble bicarbonates.

Another option to reduce $\mathrm{pH}$ is adding acid in the solution. Besides the fact that acid is more complex to control, since small quantities can cause large variations in the $\mathrm{pH}$ level, this option might cause many operational risks, e.g. burning, respiratory problems and explosions, whether in combined with other substances. Ripke et al. [2] tested the addition of $\mathrm{CO}_{2}$ gas to reduce the $\mathrm{pH}$ in vacuum disk filters and achieved an improvement of filtration rates by $20 \%$ when dosing at $1.2 \mathrm{lbs} /$ ton of magnetite concentrate. Eisele et al. [6] observed 23\% improvement in magnetite ore filtration rate. Haselhuhn et al. [12] investigated the effect of $\mathrm{CO}_{2}$ in hematite slurry filtration and explained that filtration rate increases due to a decrease in specific filter cake resistance.

Carbonate saturation in water has been an issue for a long time in industry, in 1936, Langelier [4] derived a $\mathrm{pH}_{\text {saturated }}$ equation represented by Eqs. 1 and 2, which evaluated potential scale or corrosion tendencies based upon impurities in the water. The ideal number is zero, meaning neither scale nor corrosion formation. However, values near zero $(\mathrm{LSI}=0)$, means a water stability, neither scale-formation nor scale removing. If the index is positive ( $\mathrm{LSI}>0$ ), $\mathrm{pH}_{\text {saturated }}$ equation indicates that water will form calcium carbonates $\mathrm{CaCO}_{3}$ (oversaturation). The calcium carbonates will be deposited in the system. If the value is negative $(\mathrm{LSI}<0)$, the index indicates a corrosive behaviour of the water, the system will be undersaturated with calcium carbonate, causing removal on the protective coatings in pipes and equipment. Although, several different new approaches can be additionally considered and [13] reveals the relevance of stability index proposed by Langelier with real operations.

$\mathrm{LSI}=\mathrm{pH}_{\text {water }}-\mathrm{pH}_{\text {saturated }}$

When LSI is Langelier's saturation Index (or Calcium Carbonate Saturation Index), $\mathrm{pH}_{\text {water }}$ is the $\mathrm{pH}$ of the water measured by $\mathrm{pH}_{\text {meter }} \mathrm{pH}_{\text {saturated }}$ is the $\mathrm{pH}$ calculated by the Langelier Index for the slurry condition.

$p H_{\text {saturated }}=p C a+p A l k+C$

$\mathrm{pCa}$ is the water hardness using $\mathrm{CaCO}_{3}$, pAlk is the total alkalinity using $\mathrm{CaCO}_{3}$ and " $\mathrm{C}$ " is the total solid in water.

For the carbonate equilibrium, the most important elements are carbon dioxide $\left(\mathrm{CO}_{2}\right)$, aqueous carbon dioxide $\left(\mathrm{CO}_{2}\right)_{\mathrm{aq}}$, carbonic acid $\left(\mathrm{H}_{2} \mathrm{CO}_{3}\right)$, bicarbonate $\left(\mathrm{HCO}_{3-}\right)$, carbonates $\left(\mathrm{CO}_{2-}\right)$ and solids containing carbonate, like calcium carbonates $\left(\mathrm{CaCO}_{3}\right)$ or magnesium carbonates $\left(\mathrm{MgCO}_{3}\right)$.

The objective of the present study is to evaluate carbonate scale formation at different $\mathrm{pH}$ ranges, to determine possible ways to handle slurry in a lower $\mathrm{pH}$ range without generating carbonate deposits in filtration components and to validate the benefits of this modification at the iron ore filtration plants. It was performed bench scale tests and industrial pilot tests to validate the results.

\section{Experimental}

\subsection{Raw materials preparation}

Industrial Itabirite concentrate was obtained from the filtration plant. Chemical characterization is presented in Table 1. The Fe (\%) analysis was performed following ISO 2597-2. $\mathrm{Fe}_{2} \mathrm{O}_{3}$ was obtained by stoichiometry calculation based on the total $\mathrm{Fe}(\%)$. $\mathrm{FeO}(\%)$ analysis was performed using ISO 9035. $\mathrm{SiO}_{2}(\%), \mathrm{Al}_{2} \mathrm{O}_{3}(\%), \mathrm{CaO}(\%)$, $\mathrm{MgO}(\%)$ and $\mathrm{Mn}(\%)$ analysis were performed following ISO 11,535. P (\%) analysis was performed following ISO 4687-1. Representative samples were generated by quartering and riffling sampling methods (ASTM E $877-03,2003)$. Blaine surface area (BSA) was measured according to ASTM C 204-07, 2007.

The water used in the tests was industrial water and its characteristics are presented in Table 2.

Table 1 Chemical and mineral characterization of the iron ore concentrate, dry basis

\begin{tabular}{|c|c|c|c|c|c|c|c|c|}
\hline $\mathrm{Fe}_{2} \mathrm{O}_{3}(\%)$ & $\mathrm{FeO}(\%)$ & $\mathrm{SiO}_{2}(\%)$ & $\mathrm{Al}_{2} \mathrm{O}_{3}(\%)$ & $\mathrm{CaO}(\%)$ & $\mathrm{MgO}(\%)$ & $\mathrm{Mn}(\%)$ & $\mathrm{P}(\%)$ & $-325 \#$ \\
\hline 94.29 & 1.62 & 1.59 & 0.32 & 0.02 & 0.02 & 0.083 & 0.046 & $88 \%$ \\
\hline ISO 2597-2 & ISO 9035 & ISO 11,535 & & & & & ISO 4687-1 & ISO 4701 \\
\hline \multicolumn{2}{|c|}{ \%Specular Hematite } & \multicolumn{2}{|c|}{ \%Porous Hematite } & \multicolumn{2}{|c|}{ \%Magnetite } & \multicolumn{2}{|c|}{ \%Goethite } & \%Quartz \\
\hline 45.3 & & \multicolumn{2}{|l|}{33.7} & \multicolumn{2}{|c|}{1.2} & \multicolumn{2}{|c|}{17.8} & 2 \\
\hline
\end{tabular}


Table 2 Industrial water chemical characterization

\begin{tabular}{llllll}
\hline $\begin{array}{l}\text { Colour (mg } \\
\text { Pt/L) }\end{array}$ & $\begin{array}{l}\text { Turbidity } \\
\text { (NTU) }\end{array}$ & $\mathrm{pH}$ & $\begin{array}{l}\text { Colour (mg } \\
\text { Pt/L)-MP* }\end{array}$ & $\begin{array}{l}\text { Turbidity } \\
\text { (NTU)-MP* }\end{array}$ & $\mathrm{pH}^{*}$ \\
\hline 3.00 & 1.08 & 7.4 & 15.00 & 5.00 & $7.0-7.5$ \\
\hline
\end{tabular}

${ }^{*} M P$ maximum limit permitted by Brazilian legislation

\subsection{Leaf test experiments}

Initial filtration performance was assessed in a bench apparatus. The leaf tests were performed to determine filtration rate (ton/h/filter) and the moisture content (\%). Leaf tests were performed using cycle time of $60 \mathrm{~s}$ which comprised a cake formation time of $15 \mathrm{~s}$, cake drying time of $45 \mathrm{~s}$ and pressure of $760 \mathrm{mmHg}$, using monofilament cloth, these conditions were held constant for all tests. For the bench test, it was used 3.0 litters of pulp for each single leaf test, the results presented in this chapter represent the mean average of test and replica results. The pulp contains $70 \%$ solid content. The physical characterization represents $88 \%$ passing in the 325 mesh Tyler, according to ISO 4701 procedure. Then, the cake was collected into a tray and the mass was recorded. The calculation of moisture was performed according to the ISO 3087 standard. Figure 3 represents a typical leaf test schematic.

Table 3 presents the monofilament fabric characteristics used in the leaf tests.

\subsection{Calcium carbonate deposition test}

Bench tests to evaluate the calcium carbonate deposition according to the $\mathrm{pH}$ range were developed. It is critical, since the calcium carbonate will cause a range of losses in the filtration plant. Industrial water $\mathrm{pH}$ used in the bench tests was adjusted by lime additions, increasing the $\mathrm{pH}$ to a value of 12 and adjusted back to lower values ranging from 6.0 to 11.5 by $\mathrm{CO}_{2}$ gas addition in a continuous agitation in $500 \mathrm{~mL}$ becker. Agitation was kept steady for $1 \mathrm{~h}$ at $30 \mathrm{rpm}$. The tests were carried out in 10 replications at each $\mathrm{pH}$ value. Afterwards, the solution was filtered at $0.45 \mu \mathrm{m}$ pitch filter paper. The filter paper was dried in an oven at $100^{\circ} \mathrm{C}$ until a constant weight loss. Finally, the residual material was weighted using a precision balance $(+/-0.0001 \mathrm{~g})$. The initial weight of the Millipore filter paper was considered. The $\mathrm{CO}_{2}$ gas used in the tests has concentration higher than $99.5 \%$.

\subsection{Scale-up tests}

The scale-up tests were conducted to assess the impact of different levels of $\mathrm{pH}$ on filtration process. The results were compared with another filter with similar mechanical and process conditions. Horizontal vacuum disk filter EIMCO with 10 discs of 12 sector per disc (as shown in Fig. 4) and monofilament cloth were used.

The first scale-up test was performed in On/Off method, where $\mathrm{CO}_{2}$ was added (On) in 2 different

Fig. 3 Leaf test schematic

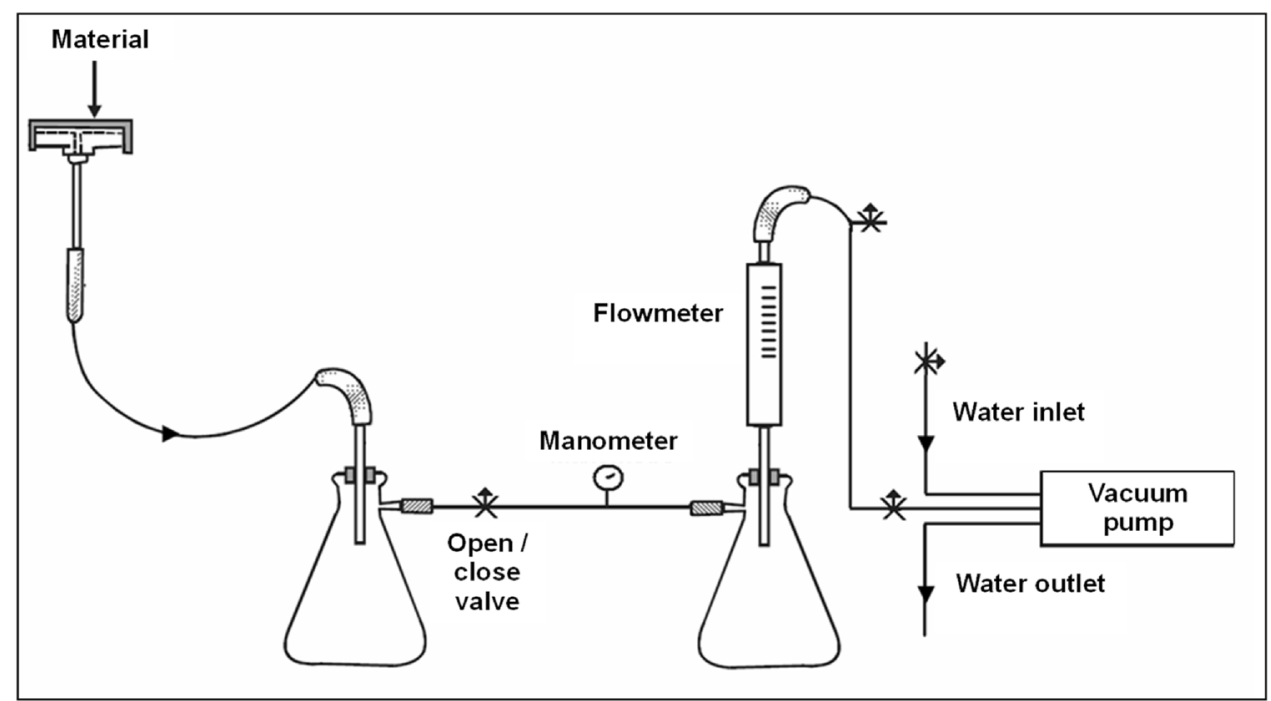

Table 3 Specification of the fabric

\begin{tabular}{llllll}
\hline Raw material & Fabric construction & Finish & Weight & Air permeability at 200 Pa & Air permeability at $1 / 2$ in $\mathrm{H}_{2} \mathrm{O}$ \\
\hline Polyamide & Monofilament & Heat-set/calendered & $204 \mathrm{~g} / \mathrm{m}^{2}$ & $27 \mathrm{M}^{3} \mathrm{~m}^{2} / \mathrm{min}$ & $270 \mathrm{l} / \mathrm{dm}^{3} / \mathrm{min}$ \\
\hline
\end{tabular}




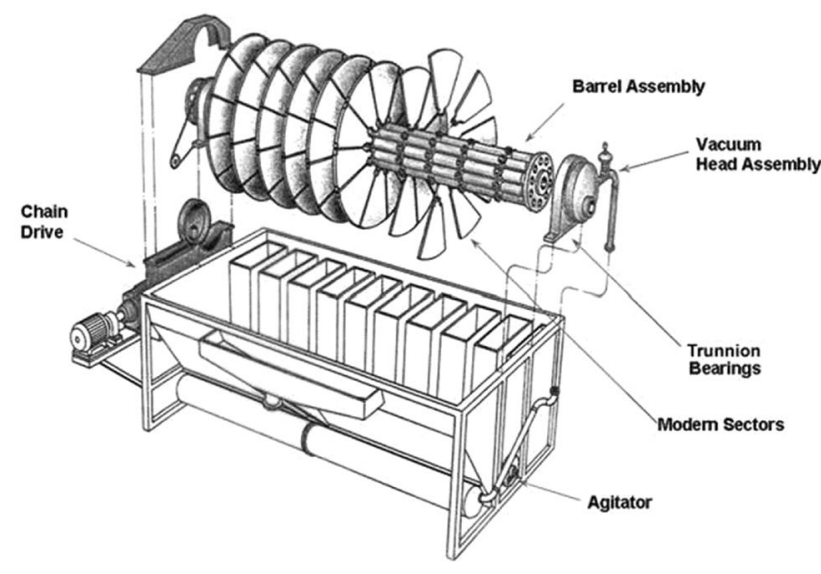

Fig. 4 Industrial filtration system (http://www.fixfilters.com) [14]

industrial filters and the results were measure in terms of filtration rate and moisture content. Then, $\mathrm{CO}_{2}$ was not added (Off) and the same parameters were measured. Filtration rate was measured by collecting material in a specific location after the filter blowing, weighting the quantity of collected material and using the rotation velocity to predict the production rate performance.

The second scale-up test were performed adding $\mathrm{CO}_{2}$ in a distribution header, this header distribute slurry for 12 industrial filters. The test was performed through $72 \mathrm{~h}$. Results were compared to filters from second distribution header that also fed 12 industrial filters without addition of $\mathrm{CO}_{2}$. This set of tests were performed to compare a group of filters in $\mathrm{pH} 7.5$ to a group of filters in $\mathrm{pH} 11.5$.

\section{Results and discussion}

In this chapter, the results of the bench scale test and also for the scale-up test will be presented divided in leaf tests experiments, scale generation tests, On/off scale-up tests and larger scale-up tests.

The bench test replicates the findings by other authors, in terms of moisture level reduction and productivity increase $[2,6,12,15,16]$. Confirming the previous Langelier's studies [4], regarding calcium carbonates deposition depending on the $\mathrm{pH}$ level.

Scale-up tests were conduced to prove the bench tests and provide real results for the operational team, represented by improvements on moisture level and increase on filter production rate.

\subsection{Leaf test experiments}

Figure 5 shows the leaf test results for filtration rate and moisture content. The optimum filtration rate was found between $\mathrm{pH} 7.0$ and 8.0 in comparison to the $\mathrm{pH} 11.0$ to 11.5 (current slurry pH level). It was observed an increase achieving $16 \%$ on filtration rate, from 67 ton/h to 78 ton/h for slurry containing $1,950 \mathrm{~cm}^{2} / \mathrm{g}$ of Blaine surface area, and decrease of $8 \%$ on moisture content, from $11.2 \%$ to $10.3 \%$ for the same slurry characteristics. Generally, Blaine surface area (BSA) is an indicative of fineness of particles and as higher is the number, more small particles size concentration will have in the solution, it means more difficulty for the filter handle the material. Therefore, $\mathrm{pH}$ around 10.0-12.0 indicates a dispersive behaviour, resulting in more struggle to allow the air pass through the filter
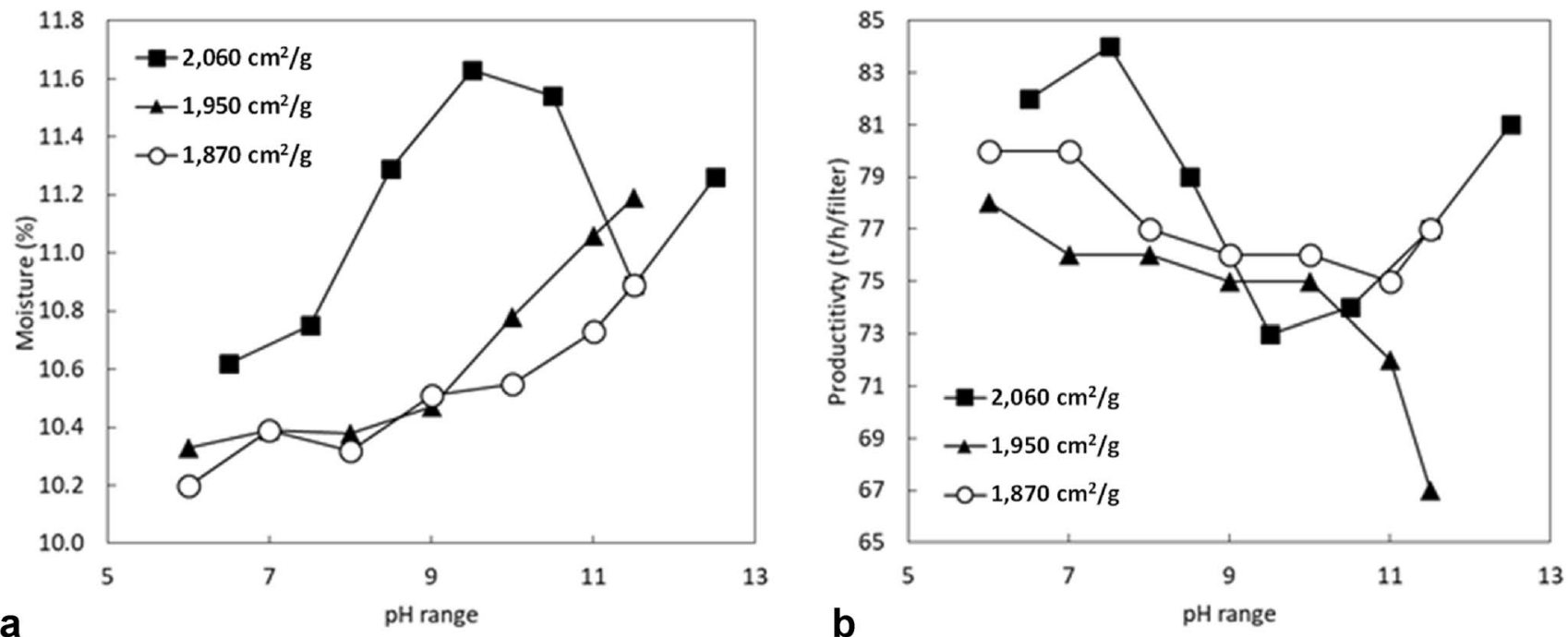

Fig. 5 a moisture content $\mathbf{b}$ throughput measured in the leaf test in different $\mathrm{pH}$ levels 
cake during filtration, it results in increase on moisture content and reduction in filtration rate.

Despite of that, the impact of the BSA was significantly higher for moisture than for filtration rate in the $\mathrm{pH}$ lower than 9.0. Clearly, lower BSA (in other words, coarser particle sizes) facilitates the process and allow strongly reduction on moisture content at any $\mathrm{pH}$ level, but cracks formation in the filter cake during drying step for $\mathrm{pH}$ over 9.0 cause a reduction on cake thickness, consequently impacting filtration rate. It is explained by the fact that when cracking occurs, there is a preferential air flow in the region. The reduction in $\mathrm{pH}$ in higher $\mathrm{BSA}$ values have a strong impact on the moisture content, it can be explained by the reduction of large ions in solution, decreasing slurry dispersion, facilitating the water removal from filter cake.

\subsection{Scale generation experiments (Langelier Saturation Index)}

Scale formation was observed varying industrial water $\mathrm{pH}$, it is shown in Fig. 6. The methodology used to evaluate the calcium carbonate formation are explained in Sect. 2.3. The scale formation data present a good third-degree curve fitting, with Pearson correlation index of $89.1 \%$. Higher scale formations were observed in $\mathrm{pH} 9.50-10.50$, as it was reported in the literature [3]. This range is where the whole quantity of $\mathrm{CO}_{2}$ contained in the solution is transformed into

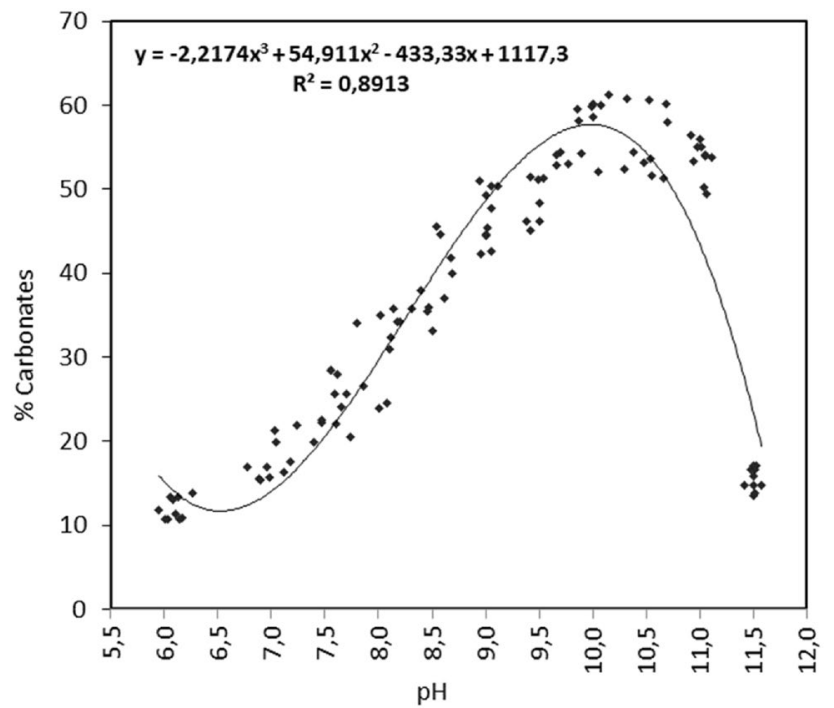

Fig. 6 Calcium carbonate deposition test calcium carbonates. As far the range is concerned, it has a great agreement with past historical operational experience, where the scale formation in pipes happens in pumps and filter components. Simultaneously, lower $\mathrm{pH}$ resulted in increase on the filtration rate and reduction on the moisture content.

Statistical assessment was performed in Minitab Statistical Software and $t$-Test for 2 Samples. This evaluation brought information about standard deviation, average and $P$-value for each group of values ( $p$-value lower than 0.05 means statistical differences between groups). Comparing the results achieved at $\mathrm{pH} 7.0-7.5$ with the results achieved at $\mathrm{pH} 11.0-11.5$, it was possible to see that carbonate deposition was $20.4 \%$ of the total lime added for the $\mathrm{pH} 7.0-7.5$ while for the $\mathrm{pH} 11.0-11.5$ this value was $34.6 \%$. Table 4 shows the results of $t$-test for 2 samples obtained by Minitab software. These results indicate the feasibility of changing the $\mathrm{pH}$ level in the operational process. In the test, $\mathrm{pH}$ range was limited to 6.0 , since $\mathrm{CO}_{2}$ shows a buffering effect at this range. The maximum $\mathrm{pH}$ tested was 11.0 , since this is the reality of pipeline process.

Figure 7 shows the Langelier saturation index for the iron ore slurry tested. According to Langelier [4], if the value of the Eq. 1 is equal zero, the water is in equilibrium, it means that it does not have the tendency of corrosion neither crystallization and subsequently carbonate deposition. If the value is positive, there are an over-saturation and tendency of carbonate crystallization. If the value is negative, there are under-saturation, that means a tendency to dissolve an existing carbonate coating. The point marked in the graph represents the value found for the $\mathrm{pH}$ applied in scale-up tests (around $\mathrm{pH}$ 7.6) and it proves that not only carbonate formation does not exist at this $\mathrm{pH}$ level, but it even tends to dissolve carbonate formation. If compare to the current $\mathrm{pH}$ level slurry in the filtration plant (around 11.0 to $11.3 \mathrm{pH}$ ), it is possible to conclude that the proposed level represents an improvement on the process.

\subsection{On/off scale-up tests}

On/Off scale-up test was conducted in 2 different filters and the results show a different behaviour of that found in leaf tests, but both beneficial for the process. The difference is that at the leaf test, moisture content was reduced with the reduction of $\mathrm{pH}$ and filtration rate kept constant. Here, the moisture kept constant and the filtration rate shows an average increase of $20 \%$, from 87.24 to 108.5 ton/h. Table 5
Table 4 t-test for 2 samples of $\%$ carbonate deposition for $\mathrm{pH}$ $7.0-7.5$ and $11.0-11.5$

\begin{tabular}{|c|c|c|c|c|c|c|c|}
\hline \multirow[t]{2}{*}{ Parameter } & \multirow[t]{2}{*}{$p$-value } & \multicolumn{4}{|c|}{$\mathrm{pH} 7.0-7.5$} & \multicolumn{2}{|c|}{$\mathrm{pH} 11.0-11.5$} \\
\hline & & Samples & Average & Std Dev & Samples & Average & Std Dev \\
\hline$\%$ Carbonate deposition & 0.005 & 17 & 20.37 & 4.23 & 20 & 34.6 & 19.7 \\
\hline
\end{tabular}




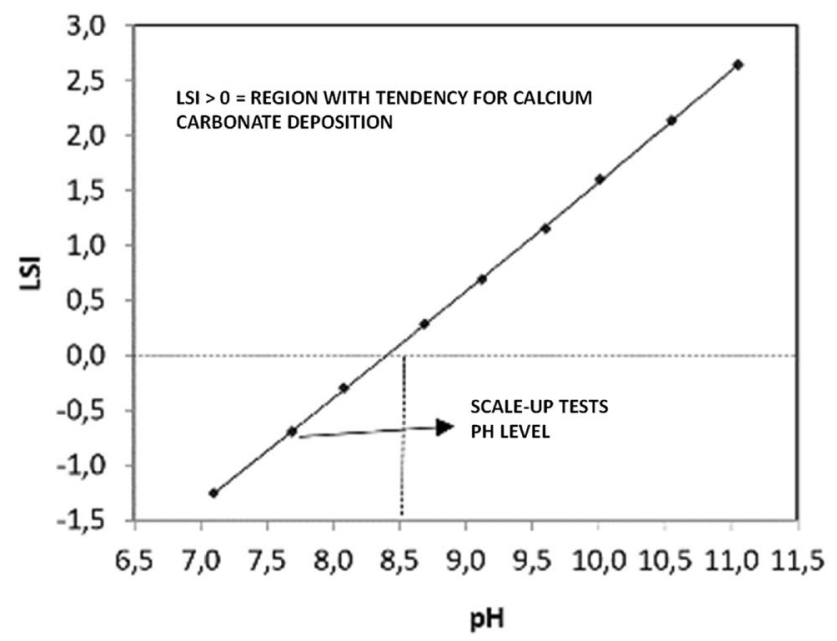

Fig. 7 Langelier Saturation Index for the iron ore slurry

shows the results ( $p$-value higher than 0.05 means statistical equality). The software used in the evaluation was Minitab Statistical Software.

\subsection{Large scale-up tests}

A large scale-up test was conducted and more complexity was observed. Table 6 summarize the results from the $72 \mathrm{~h}$ monitored test. Moisture content shows similar level comparing the filter with and without $\mathrm{CO}_{2}$ addition $(\mathrm{pH}=7.5 \times \mathrm{pH}=11.5)$. But filtration rate shows $36 \%$ increase, from 90.64 to 123.70 ton/h, in lower $\mathrm{pH}\left(\mathrm{CO}_{2}\right.$ addition). The lower $\mathrm{pH}$, close to the point of zero charge (PZC) allow the mineral particles to flocculate and less water molecules are electrostatically trapped onto the mineral surface, promoting an easy way for the vacuum flowing through the layer of pellet feed formed in the clothes. Also, a greater vacuum air flow through the sectors increased the cake thickness. $\mathrm{CO}_{2}$ injection changed the $\mathrm{pH}$ downward, thus hematite particle surface reduces potential allowing the reduction the distance among them. Unfortunately, due the complexity to keep the homogeneity of the $\mathrm{CO}_{2}$ addition during the whole test, a large standard deviation was observed.

Adittionaly, Fig. 8 shows the difference between a filter cake thickness from a filter with $\mathrm{CO}_{2}$ addition (lower $\mathrm{pH}$ ) and without $\mathrm{CO}_{2}$ addition (higher $\mathrm{pH}$ ). It is possible to see the difference in the thickness between the two samples, it is directly linked to the higher filtration rate explained in the previous paragraph.

The large scale-up test had demonstrated different behaviour of filtration performance when $\mathrm{pH}$ was modified. Table 7 present the relationship between these 2 parameters. When the slurry $\mathrm{pH}$ was setup far higher from hematite point of zero charge (PZC), moisture has

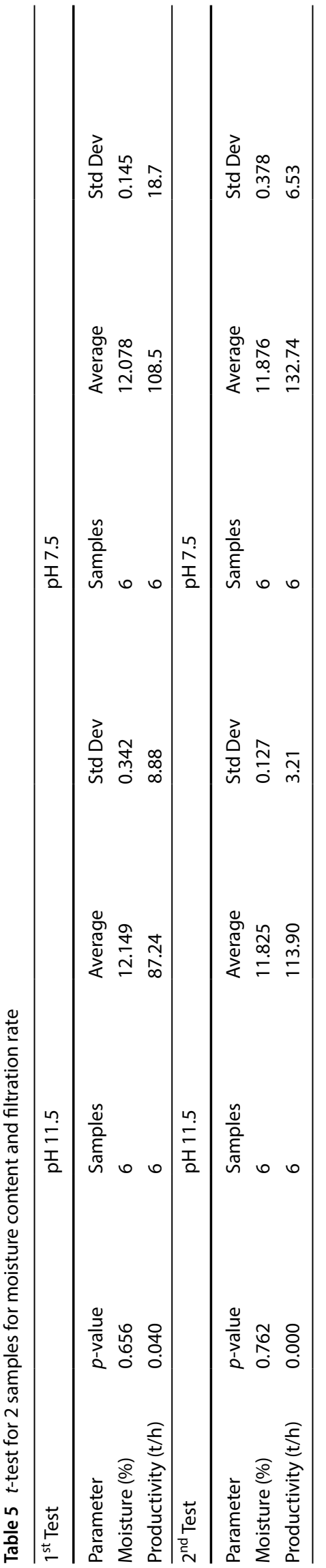

SN Applied Sciences A SPRINGER NATURE journal 
Table $6 t$-test for 2 samples for moisture and productivity comparing 36 samples of a filter with and without $\mathrm{CO}_{2}$ addition

\begin{tabular}{|c|c|c|c|c|c|c|c|}
\hline \multirow[t]{2}{*}{ Parameter } & \multirow[t]{2}{*}{$p$-value } & \multicolumn{3}{|l|}{$\mathrm{pH} 11.5$} & \multicolumn{3}{|l|}{$\mathrm{pH} 7.5$} \\
\hline & & Samples & Average & Std Dev & Samples & Average & Std Dev \\
\hline Moisture (\%) & 0.649 & 36 & 11.044 & 0.387 & 36 & 11.117 & 0.875 \\
\hline Productivity (t/h) & 0.000 & 36 & 90.640 & 8.822 & 36 & 123.70 & 14.8 \\
\hline
\end{tabular}

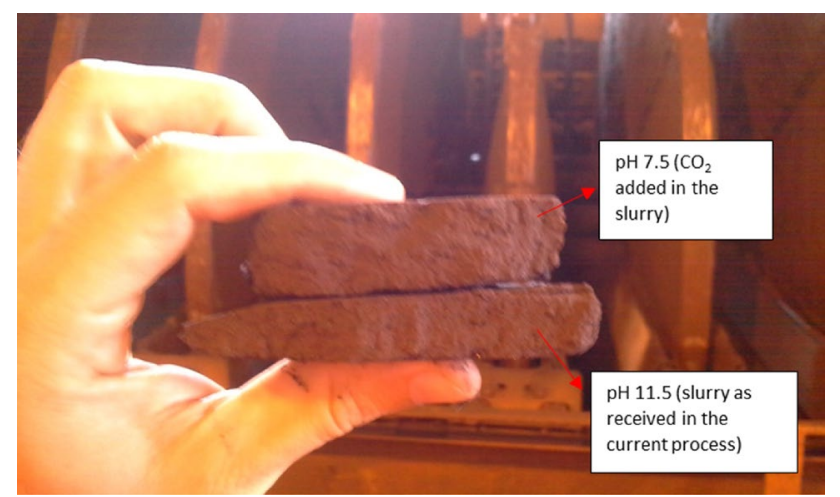

Fig. 8 Aspect of the filtration cakes in different pH levels

Table 7 Correlation between moisture and productivity for samples in $\mathrm{pH} 7.5$ and $\mathrm{pH} 11.5$

\begin{tabular}{|c|c|c|c|}
\hline \multicolumn{4}{|l|}{ Moisture (\%) } \\
\hline \multicolumn{2}{|c|}{$\mathrm{pH} 7.5$} & \multicolumn{2}{|l|}{$\mathrm{pH} 11.5$} \\
\hline Regression Eq & $\mathrm{R} 2$ & Regression Eq & $\mathrm{R} 2$ \\
\hline $\begin{array}{l}9.814+0.01177 * \text { Filtration } \\
\text { rate }\end{array}$ & 61.1 & $\begin{array}{l}10.26+0.008645 * \text { filtration } \\
\text { rate }\end{array}$ & 1.1 \\
\hline
\end{tabular}

low correlation with filtration rate ( $\mathrm{R} 2 \mathrm{adj}=1.1 \%)$. In the region where the superficial electric charge is equilibrated, filtration rate is superior and there are a strong correlation ( $p$-value $<0.05$ ) with the moisture content ( $\mathrm{R} 2 \mathrm{adj}=61.1 \%)$, allowing a better control of the filter.

\section{Conclusions}

The results presented in this paper is a significant improvement in the vacuum disk filter plant performance, since $\mathrm{CO}_{2}$ addition in filtration process show an advantage to be implemented in an industrial practice, showing around $36 \%$ increase on filtration rate, from 90.64 to $123.70 \mathrm{ton} / \mathrm{h}$, at the same moisture level. It was observed that the improvement is directly related to the slurry zeta potential presented by the $\mathrm{pH} 7.0-7.5$ compared to the $\mathrm{pH} 11.0-11.5$. When the slurry $\mathrm{pH}$ is set far from the hematite point of zero charge ( $P C Z)$, the ionic concentration increases considerably in the slurry, unbalanced, adsorption of divalent cations on the hematite surfaces, resulting in electrostatic attraction between these particles. When the slurry $\mathrm{pH}$ is closer to the point of zero charge of the hematite, the particles in the slurry tend to have a balance in the charges, reducing the electrostatic forces between the hematite particles and the ions present in the slurry. The reduction on $\mathrm{pH}$ level to 7.0-7.5 promoted to be able to reduce the amount of scale formation in filters sectors, clothes, vacuum pumps and tubes. With that, fabric lifetime will increase, shutdowns for fabric and sectors replacements will reduce, as well as interventions on vacuum pumps will decrease. It represents costs reduction and plant availability increase. Scale-up tests corroborate the results achieved in bench tests. Langelier's saturation index was applied at the iron ore slurry tested. Carbonate stability curve was also used in the tests and proved to be useful. Calcium carbonate deposition test was developed and applied, the results fits to the literature. Tests in longer period of time must be conducted to evaluate the real $\mathrm{CO}_{2}$ gas consumption and the benefits of the proposed modification in the filtration plant, pelletizing and firing process.

\section{Declaration}

Conflict of interest On behalf of all authors, the corresponding author states that there is no conflict of interest.

Open Access This article is licensed under a Creative Commons Attribution 4.0 International License, which permits use, sharing, adaptation, distribution and reproduction in any medium or format, as long as you give appropriate credit to the original author(s) and the source, provide a link to the Creative Commons licence, and indicate if changes were made. The images or other third party material in this article are included in the article's Creative Commons licence, unless indicated otherwise in a credit line to the material. If material is not included in the article's Creative Commons licence and your intended use is not permitted by statutory regulation or exceeds the permitted use, you will need to obtain permission directly from the copyright holder. To view a copy of this licence, visit http://creativecommons .org/licenses/by/4.0/.

\section{References}

1. Senapati PK, Panda D, Parida A (2009) Predicting viscosity of limestone-water slurry. J Minerals Materials Charact Eng 08(03):203-221. https://doi.org/10.4236/jmmce.2009.83018 
2. Ripke SJ et al. (2013) Improving magnetite concentrate filtration rates with carbon dioxide addition. SME Annual Meeting, Preprint 04-81

3. Turrer HD, Gatti AM, Junior A, Doellinger TM, Zuchi MA, Peres AEC (2010) Uso de coagulantes para manutenção do desempenho da filtragem de minério de ferro. Tecnologia Em Metalurgia E Materiais 7(1-2):42-48. https://doi.org/10.4322/ tmm.00701008

4. Langelier WF (1936) The analytical control of anti-corrosion water treatment. AWWA 28:1500

5. Silva AM, Paniago EB, Faria DLA, Wendling F, Otaviano MM (2007) Caracterização Do Processo De Degradação De Uma Fibra De Poliamida Utilizada Como Tecido Filtrante Na Filtragem De Uma Polpa De Minério De Ferro. Tecnologia Em Metalurgia E Materiais 3(3):28-33. https://doi.org/10.4322/tmm.00303006

6. Eisele TC, Kawatra SK, Ripke SJ (2005) Water chemistry effects in iron ore concentrate agglomeration feed. Miner Process Extr Metall Rev 26(3-4):295-305. https://doi.org/10.1080/08827 500590944063

7. Carlson JJ, Kawatra SK (2013) Factors affecting zeta potential of iron oxides. Miner Process Extr Metall Rev 34(5):269-303. https ://doi.org/10.1080/08827508.2011.604697

8. Lopes GM, Lima RMF (2009) Flotação direta de minério de ferro com oleato de sódio. Rem Rev Esc Minas 62(3):323-329. https ://doi.org/10.1590/S0370-44672009000300010

9. Pan Z (2004) Interactions of cationic dendrimers with hematite mineral, colloids and surfaces a: physicochem. Eng Aspects 238:123-126

10. Quast K (2012) Effects of pretreatments on the zeta potential characteristics of a hematite ore. Int J Min Eng Mineral Process 1(2):47-55. https://doi.org/10.5923/j.mining.20120102.05
11. Athayde $M$ et al (2018) A case study of pellet size fraction influence on pelletizing operation. Mineral Process Extractive Metall Rev. https://doi.org/10.1080/08827508.2017.1423296

12. Haselhuhn HJ, Swanson KP, Kawatra SK (2012) The effect of CO2 sparging on the flocculation and filtration rate of concentrated hematite slurries. Int J Mineral Process 112-113:107-109. https ://doi.org/10.1016/j.minpro.2012.04.006

13. Alimoradi J et al (2018) Data on corrosive water in the sources and distribution network of drinking water in North of Iran. Data Brief 17:105-118. https://doi.org/10.1016/j.dib.2017.12.057

14. Rotary vacuum disc filter basics. Vacuum filter disc basics. Accessed April 04, 2018. http://www.fixfilters.com/Vacuum-Filte r-Disc-Basics.html

15. Araujo Junior AM, Peres AEC, Turrer HDG, Fonseca MC, Behring RS, Doellinger TM, Passigati VP (2009) Effect of lime addition on the filtration and balling processes. Proceedings of the XXIII ENTMME, 8 pp. In Portuguese

16. Bragança AC, Silva TA (2004) A study of the effect of lime addition on the behavior of the concentrate of iron ore from the Alegria Complex along the pipeline of Samarco Mineração S.A. 16th International Conference on Hydrotransport. Santiago

Publisher's Note Springer Nature remains neutral with regard to jurisdictional claims in published maps and institutional affiliations. 